\title{
Giant schwannomas of the sciatic nerve
}

\author{
Mohammed As-Sultany, ${ }_{1}^{1}$ Najla Ben-Ghashir, ${ }^{2}$ Alpesh Mistry, ${ }^{3}$ Coonoor Chandrasekar ${ }^{1}$
}

${ }^{1}$ Department of Trauma and Orthopaedics, Royal Liverpool and Broadgreen University Hospitals NHS Trust, Liverpool, UK

${ }^{2}$ Department of Pathology Services, Royal Liverpool and Broadgreen University Hospitals NHS Trust, Liverpool, UK

${ }^{3}$ Department of Radiology, Royal Liverpool and Broadgreen University Hospitals NHS Trust, Liverpool, UK

\section{Correspondence to} Mohammed As-Sultany, msultany@doctors.org.uk

Accepted 26 June 2017

\section{SUMMARY}

We report a very rare case of giant schwannomas of the sciatic nerve in a 39-year-old woman who presented with increasing swelling and discomfort in the posterior aspect of her right thigh. We demonstrate that even with such large tumours, surgical excision could be successfully carried out to resolve all symptoms while causing no permanent nerve damage. It remains paramount that large soft tissue tumours get referred to a sarcoma centre and be managed by a specialist multidisciplinary team.

\section{BACKGROUND}

Schwannomas are slow-growing nerve sheath tumours derived from well-differentiated schwann cells in the peripheral nervous system. ${ }^{1}$ They are usually solitary lesions, but may be found in larger numbers when associated with any of the genetically inherited (autosomal dominant) conditions of neurofibromatosis type 1 (NF1), neurofibromatosis type 2 (NF2) or schwannomatosis. Schwannomas are mainly benign with only about $1 \%$ of cases having malignant potential when associated with NF1. ${ }^{23}$ Although they commonly occur in the head and neck region (eg, vestibular schwannomas), they have also been found in the retroperitoneal space, pelvis and extremities. ${ }^{4}$ More specifically, these tumours are very rare and we report a unique case of giant sciatic nerve schwannomas. To the best of our knowledge, there are no other reports describing such giant sciatic nerve schwannomas.

\section{CASE PRESENTATION}

A 39-year-old woman was referred to our tertiary sarcoma centre on July 2013 with a 6-month history of a swelling of the posterior aspect of her right thigh. She reported that the swelling had been increasing in size and becoming more noticeable and uncomfortable especially when sitting down. She did not complain of any radicular nerve pain or neurological deficit to the limb. There was no history of any local trauma and she had no significant medical history or family history. On examination, there was a large, deep, firm, very tender swelling below the right gluteal crease. Although this swelling was very tender, it did not cause any pain radiating down the leg and there was no evidence of sciatic nerve dysfunction. There was no palpable lymphadenopathy.

\section{INVESTIGATIONS}

The patient had an MRI scan, which demonstrated a $\quad 4.1 \times 5.4 \times 11 \mathrm{~cm}$ (medial-lateral $\times$ anterior-posterior $\times$ cranialcaudal) and an adjacent $3 \times 3.5 \times 6 \mathrm{~cm}$ lesion in the posterior compartment with features of a neurogenic tumour (figures 1-3). Due to its size, an ultrasound-guided biopsy was performed and the histological appearance was consistent with a benign schwannoma.

\section{TREATMENT}

This result was discussed with the patient together with the potential risks and benefits of surgical excision. Due to the severity of pain, the patient decided to have surgery despite knowing there was a small risk of permanent sciatic nerve damage and loss of function.

The surgery was performed under general anaesthetic with the patient in the prone position. A longitudinal midline skin incision was made over the posterior aspect of the right thigh. Once in the posterior compartment, the large schwannomas and their relation to the sciatic nerve were identified. With careful dissection, the tumours were enucleated en-mass preserving the sciatic nerve. The soft tissues were closed in layers after achieving haemostasis.

The macroscopic histological description was that the specimen comprised two separate encapsulated ovoid lumps. The larger one weighed $111 \mathrm{gm}$ and measured $4.5 \times 6 \times 12 \mathrm{~cm}$, whereas the second one weighed $27 \mathrm{gm}$ and measured $3 \times 3.5 \times 6 \mathrm{~cm}$. The microscopic histology showed both tumours composed of bundles of spindle cells containing dark wavy nuclei and dense eosinophilic cytoplasm with ill-defined borders and nuclear palisading. The excision margins appeared complete with no evidence of malignancy. This appearance is consistent with a benign schwannoma (figures 4 and 5).

\section{OUTCOME AND FOLLOW-UP}

The patient was well postoperatively with no signs of any neurovascular deficit. During routine follow-up, the wound had healed well and she was back to normal activities with no evidence of any neurological deficit or posterior thigh pain. She is well with no further symptoms 3 years following surgery.

\section{DISCUSSION}

Schwannomas are the most common peripheral nerve sheath tumours, which tend to be found equally in male and female patients aged between 20 and 50 years. Although these benign and solitary tumours are rare, sciatic nerve schwannomas are 


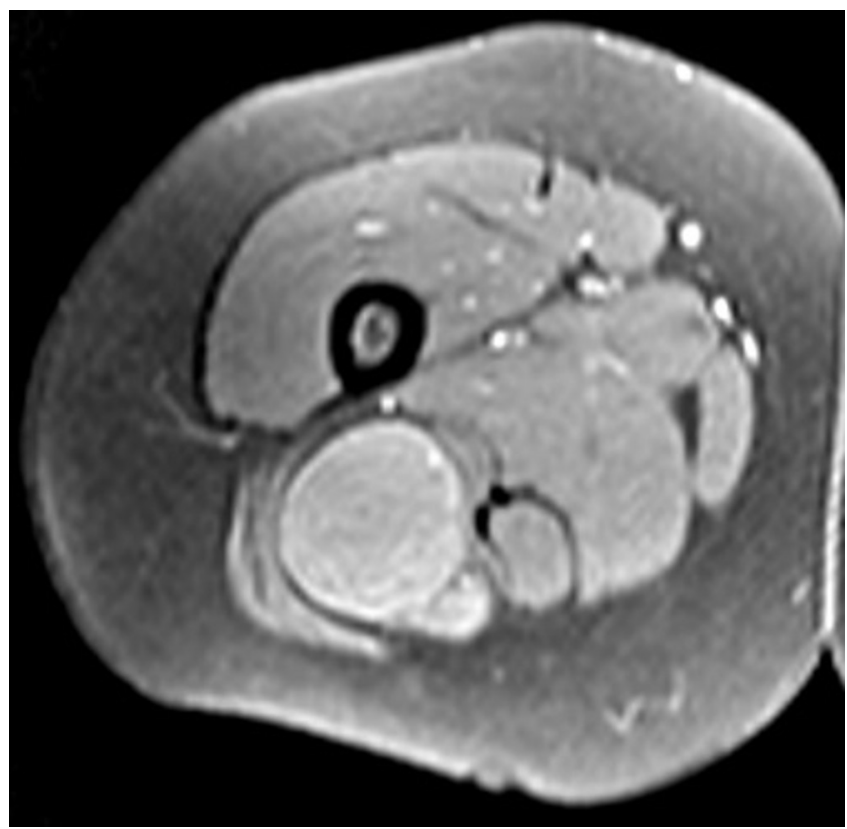

Figure 1 Axial T1-weighted MRI of the right thigh shows the typical homogeneous isointense signal of the sciatic nerve schwannomas.

even rarer with an estimated incidence of six cases per million people. $^{56}$

As peripheral nerve schwannomas expand within a confined space, they typically cause local discomfort and radicular pain. ${ }^{7}$ As described by several case reports, however, this type of presentation for a sciatic nerve schwannoma can easily be attributed to degenerative spinal pathology. ${ }^{9-13}$ The clinician should be alerted to a non-discogenic cause of sciatica, when the radicular pain fails to improve with anti-inflammatory medication and activity modification, the patient has a normal spinal examination and there is no evidence of disc herniation on the lumbar spine MRI scan. It is therefore, very important to obtain a detailed history and perform a thorough limb examination.

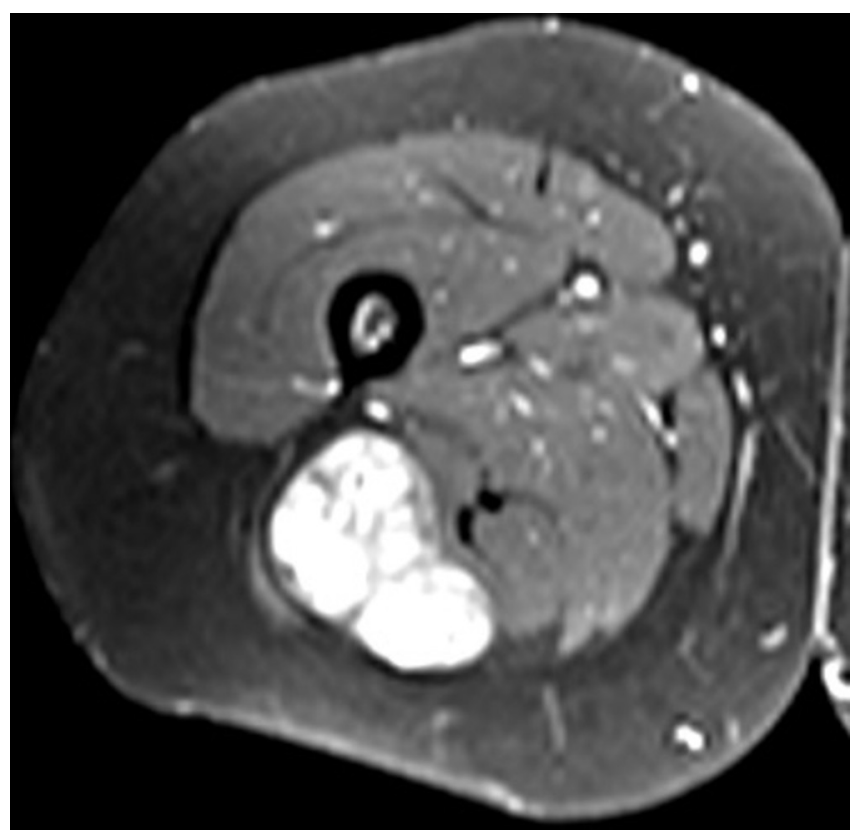

Figure 2 Axial postgadolinium-weighted MRI of the right thigh shows the enhancement of the sciatic nerve schwannomas.

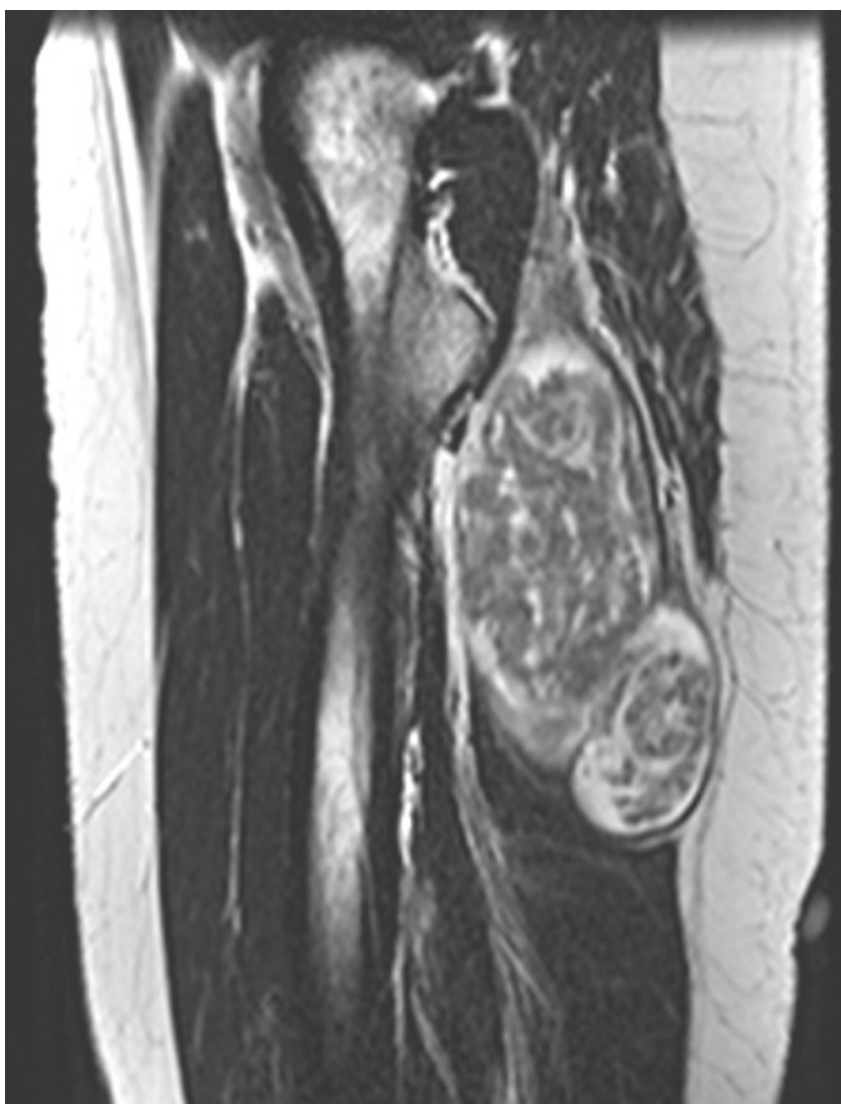

Figure 3 Sagittal T1-weighted MRI of the right thigh. Well-defined, lobulated and eccentrically located giant sciatic nerve schwannomas showing some heterogeneous signal possibly due to flow voids and serpentine small vessels.

The current case in which our patient presented with only localised deep swelling and discomfort and not the typical radicular leg pain further highlights this.

Once a neurogenic tumour is clinically suspected, it needs to be imaged with an MRI scan, which is the gold standard investigation for all large soft tissue swellings. ${ }^{14}$ This imaging modality will aid in differentiating schwannomas from the other main diagnosis of neurofibromas. Schwannomas are well circumscribed,

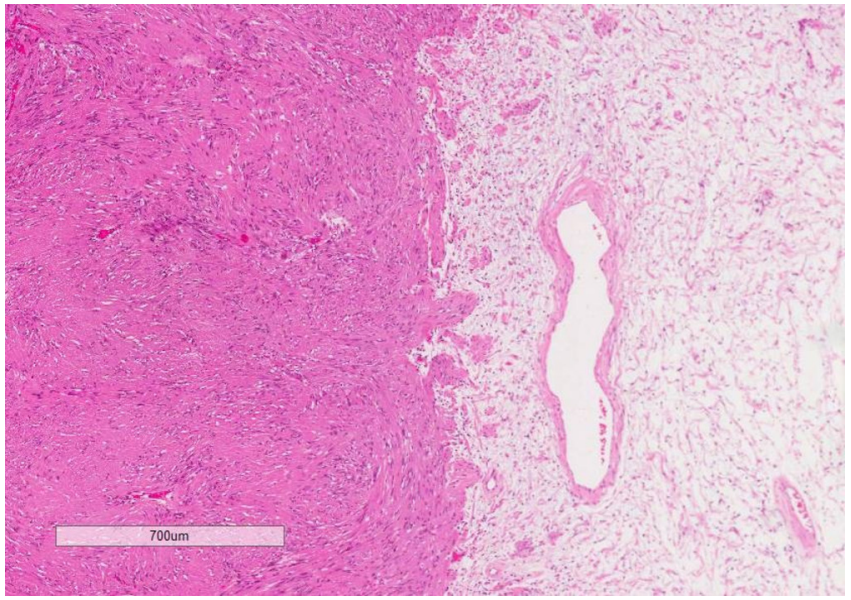

Figure 4 Photomicrography of histological tissue, demonstrating the characteristic Antoni A (left) and Antoni B (right) areas of the schwannoma (H\&E stain). 


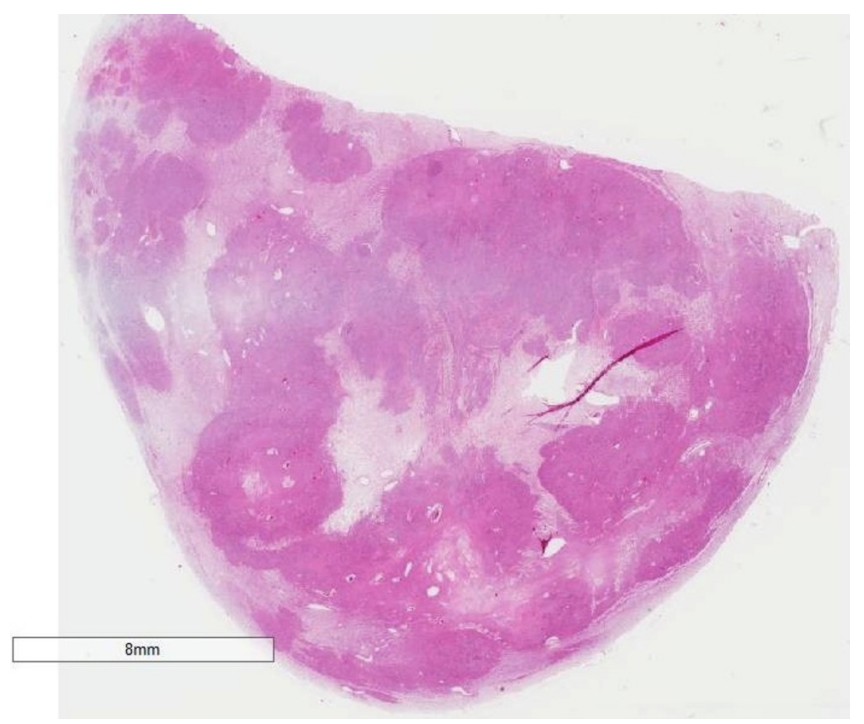

Figure 5 Photomicrography of histological tissue, showing the wellcircumscribed schwannoma containing the variation in cellularity ( $H \& E$ stain).

encapsulated tumours, which are eccentrically located on proximal nerve roots. On the other hand, neurofibromas tend to be multiple, have no clear capsule and cause central fusiform enlargement of distal nerves. ${ }^{13}$ Characteristically, schwannomas have a homogenous appearance on both T1-weighted and T2-weighted MRIs, while neurofibromas have a heterogeneous signal on both. However, very large schwannomas can also be heterogeneously enhanced as shown in figure 3 from the current case. $^{15}$

Obtaining a biopsy using ultrasound guidance is necessary when dealing with any rapidly growing soft tissue sarcoma larger than $5 \mathrm{~cm}$ in diameter and having a heterogeneous appearance on MRI. As these three features were present in the current case, an urgent ultrasound-guided biopsy ruled out malignancy and confirmed a benign schwannoma. These tumours have a

\section{Learning points}

Benign nerve sheath tumours can be large and mimic sarcomas.

- Large, enlarging soft tissue lumps are referred to sarcoma centres for appropriate investigations and management.

- Giant benign nerve sheath tumours (schwannomas) can be surgically excised with no residual neurological deficit. characteristic histological appearance of alternating distinctive Antoni A and Antoni B areas. The former represents cellular spindle cell areas rich in palisaded Verocay bodies, while Antoni $\mathrm{B}$ areas are less cellular with loose myxoid stroma (figures 4 and 5). ${ }^{16}$

Surgical excision of schwannomas is the treatment of choice to prevent potential neurological injury by compression and eliminate the possibility of malignant transformation. ${ }^{3}$ Although the structural nature of these tumours allows their enucleation, great care must be taken not to disrupt neural continuity.

Contributors MA-S: wrote the manuscript. NB-G: reported the histological findings and provided the required slide photographs. AM: reviewed and reported all included radiology. CC: involved in the management of the patient and edited the manuscript.

Competing interests None declared.

Patient consent Obtained.

Provenance and peer review Not commissioned; externally peer reviewed.

(c) BMJ Publishing Group Ltd (unless otherwise stated in the text of the article) 2017. All rights reserved. No commercial use is permitted unless otherwise expressly granted.

\section{REFERENCES}

1 Knight DM, Birch R, Pringle J. Benign solitary schwannomas: a review of 234 cases. J Bone Joint Surg Br 2007:89:382-7.

2 Woodruff JM, Selig AM, Crowley K, et al. Schwannoma (neurilemoma) with malignant transformation a rare, distinctive peripheral nerve tumour. Am J Surg Pathol 1994;18:882-95

3 Sehgal VN, Gupta RL, Bhatia A, et al. Solitary cellular schwannoma (neurilemmoma) showing malignant changes: evaluation through magnetic resonance imaging (MRI), surgical intervention and histopathology. J Dermato/ 1999;26:189-95.

4 Birch R, Bonney G, Wynn Parry CB. The peripheral nervous system and neoplastic disease. Churchill Livingstone. Edinburgh: Surgical disorders of peripheral nerves, 1998:335-52.

5 Kralick F, Koenigsberg R. Sciatica in a patient with unusual peripheral nerve sheath tumors. Surg Neurol 2006;66:634-7.

6 Nawabi DH, Sinisi M. Schwannoma of the posterior tibial nerve: the problem of delay in diagnosis. J Bone Joint Surg Br 2007;89:814-6.

7 Godkin O, Ellanti P, O'Toole G, O'Toole G. Large schwannoma of the sciatic nerve. BMJ Case Rep 2016;2016.

8 Eroglu U, Bozkurt M, Ozates 0 , et al. Sciatic nerve schwannoma: case report. Turk Neurosurg 2014;24:120-2.

9 Omezzine SJ, Zaara B, Ben Ali M, et al. A rare cause of non discal sciatica: schwannoma of the sciatic nerve. Orthop Traumato/ Surg Res 2009;95:543-6.

10 Rhanim A, El Zanati R, Mahfoud M, et al. A rare cause of chronic sciatic pain: schwannoma of the sciatic nerve. J Clin Orthop Trauma 2013;4:89-92.

11 Haspolat Y, Ozkan FU, Turkmen I, et al. Sciatica due to schwannoma at the sciatic notch. Case Rep Orthop 2013;2013:1-3.

12 Mansukhani SA, Butala RR, Shetty SH, et al. Sciatic nerve schwannoma: a case report. J Orthop Surg 2015;23:259-61.

13 Chikkanna JK, Gopal S, Sampath D. Mystery of Sciatica Resolved - A Rare Case Report. J Clin Diagn Res 2016;10:4-5.

14 Zhang Z, Deng L, Ding L, et al. MR imaging differentiation of malignant soft tissue tumours from peripheral schwannomas with large size and heterogeneous signal intensity. Eur J Radiol 2015;84:940-6.

15 Pilavaki M, Chourmouzi D, Kiziridou A, et al. Imaging of peripheral nerve sheath tumors with pathologic correlation: pictorial review. Eur J Radiol 2004;52:229-39.

16 Goldblum JR, Folpe AL, Enzinger WSW, et al. Weiss's soft tissue tumours. 6th ed. Philadelphia: Elsevier Saunders, 2013. 
Rare disease

Copyright 2017 BMJ Publishing Group. All rights reserved. For permission to reuse any of this content visit http://group.bmj.com/group/rights-licensing/permissions.

BMJ Case Report Fellows may re-use this article for personal use and teaching without any further permission.

Become a Fellow of BMJ Case Reports today and you can:

- Submit as many cases as you like

- Enjoy fast sympathetic peer review and rapid publication of accepted articles

- Access all the published articles

- Re-use any of the published material for personal use and teaching without further permission

For information on Institutional Fellowships contact consortiasales@bmjgroup.com

Visit casereports.bmj.com for more articles like this and to become a Fellow 